\title{
MATRIMONIO IGUALITARIO: EL INADECUADO CAMINO EN LA BÚSQUEDA DE LA IGUALDAD MATERIAL
}

SAME SEX MARRIAGE: THE INAPPROPRIATE WAY IN THE SEARCH FOR EQUAL EQUALITY

\section{Rodrigo Durango Cordero*}

Resumen: En el año 2019 la Corte Constitucional emitió dos sentencias que, en pocas palabras, viabilizan legalmente el matrimonio igualitario en el Ecuador o de personas del mismo sexo. Estas sentencias fueron remitidas a la Corte a través del procedimiento de consulta de norma, con arreglo al art. 428 de la Constitución de la República del Ecuador con el fin de que el máximo tribunal de justicia constitucional del país ejerza el control concreto de constitucionalidad, con respecto a disposiciones legales que atañen al matrimonio civil y de la Opinión Consultiva 24 de la Corte Interamericana de Derechos Humanos de 24 de noviembre de 2017, solicitada por la República de Costa Rica relativa a la identidad de género, e igualdad y no discriminación a parejas del mismo sexo. El objetivo del presente trabajo es realizar una crítica a la construcción argumentativa de la Corte en estos dictámenes, al demostrar que dicho organismo arribó a conclusiones inconsistentes sobre la base de premisas incorrectas. Para este efecto, la metodología utilizada es la hipotética-deductiva, a la luz de la crítica argumentativa que ha sido mencionada. El trabajo está compuesto por las siguientes líneas de análisis: Primero, la desnaturalización del control concreto de constitucionalidad. Segundo, la interpretación efectuada a los enunciados normativos aplicables. Tercero, acerca del valor jurídico de las

\footnotetext{
* Máster en Estudios Legales Internacionales por Washington College of Law de American University (Estados Unidos). Docente en la Universidad Regional Autónoma de los Andes, Instituto de Altos Estudios Nacionales, Universidad de Otavalo, Universidad Indoamérica, y Universidad Técnica de Ambato (Ecuador).rdurangocordero@ hotmail.com
} 
opiniones consultivas de la Corte Interamericana. Finalmente, algunas conclusiones que abonarán el debate académico.

Palabras clave: Matrimonio mixto, constitución, derecho constitucional, derechos humanos, discriminación por orientación sexual

Abstract: In 2019, the Constitutional Court issued two sentences that, in a nutshell, legally make equal marriage in Ecuador or of same-sex persons legally viable. These sentences were sent to the Court through the procedure of consultation of norm, in accordance with article 428 of the Constitution of the Republic of Ecuador in order that the maximum constitutional justice court of the country exercise the concrete control of constitutionality, with regarding legal provisions that concern civil marriage and Advisory Opinion 24 of the Inter-American Court of Human Rights of November 24, 2017, requested by the Republic of Costa Rica regarding gender identity, and equality and non-discrimination Same-sex couples. The objective of this paper is to criticize the argumentative construction of the Court in these opinions, by demonstrating that said body arrived at inconsistent conclusions based on incorrect premises. For this purpose, the methodology used is hypothetical-deductive, in the light of the argumentative criticism that has been mentioned. The work is composed of the following lines of analysis: First, the denaturation of the concrete control of constitutionality. Second, the interpretation made to the applicable normative statements. Third, about the legal value of the advisory opinions of the Inter-American Court. Finally, some conclusions that will pay for the academic debate.

Keywords: Mixed marriage, Constitution, Constitutional Law, Human rights, Sex orientation discrimination

Sumario. I. Introducción. II. La desnaturalización del control concreto de constitucionalidad. III. La interpretación de los enunciados normativos aplicables. $I V$. Sobre el valor jurídico de las opiniones consultivas de la Corte Interamericana. $V$. Posibles soluciones y consideraciones adicionales. VI. Conclusiones. Referencias.

\section{INTRODUCCIÓN}

En meses pasados la Corte Constitucional (en adelante "la Corte") emitió dos sentencias que, en pocas palabras, viabilizan legalmente el matrimonio igualitario en el Ecuador o de personas del mismo sexo. Estas sentencias fueron remitidas a la Corte a través del procedimiento de consulta 
de norma, con arreglo al art. 428 de la Constitución de la República del Ecuador (en adelante "la Constitución") con el fin de que el máximo tribunal de justicia constitucional del país ejerza el control concreto de constitucionalidad, con respecto a disposiciones legales que atañen al matrimonio civil y de la Opinión Consultiva 24 de la Corte Interamericana de Derechos Humanos (en adelante "Corte Interamericana") de 24 de noviembre de 2017, solicitada por la República de Costa Rica relativa a la identidad de género, e igualdad y no discriminación a parejas del mismo sexo (en adelante "OC 24/17"). Sin lugar a dudas, estas decisiones no han estado alejadas de las polémicas de toda índole: jurídica, social, religiosa, moral, etc., en un país donde existe una mayoría abrumadoramente católica y las instituciones eclesiásticas tienen su peso específico dentro de la sociedad. El análisis que se realizará en el presente ensayo es una crítica a la construcción argumentativa realizada por la Corte, la cual ha llevado a este tribunal a conclusiones inconsistentes sobre la base de premisas incorrectas.

Incluso, antes de la promulgación de estas decisiones, existía un debate sobre cuál es el camino correcto que se debía seguir con el fin de legalizar esta institución en nuestro ordenamiento jurídico: interpretar la Constitución o modificarla. Las conclusiones de las dos sentencias y del voto salvado de ambas sugieren que esta discusión se llevó a cabo en el Pleno de la Corte y, por ello, la decisión tan dividida.

Conviene advertir al lector que, a pesar de esta posición crítica frente a la argumentación efectuada por la Corte, si nuestra Constitución garantiza el derecho a la igualdad formal y material y que nadie puede ser discriminado por ninguna razón, entre las cuales se incluye la orientación sexual, el Constituyente cometió un grave error de técnica legislativa al incluir una definición de matrimonio dentro del texto constitucional. Esta redacción es la que ha generado tan polémico debate en la academia ecuatoriana. No obstante, es el texto aprobado y vigente, que siguió el procedimiento establecido para el efecto y eso no puede dejar de ser considerado dentro del presente análisis.

En una publicación reciente, Stefano Rodotà se pregunta si el derecho y el amor son incompatibles o están enfrentados, si son lógicas en mutuo conflicto. El derecho, afirma, ha encerrado al amor en el único parámetro legítimo del matrimonio: un contrato de derecho público, vigilado por el Estado, basado en la estabilidad social, la procreación y la educación de los hijos y portador de una moralidad hegemónica. De este modo, es posible sostener que en la actualidad se asiste a un progresivo reconocimiento de los derechos del amor en el orden jurídico. No obstante, analiza este autor, si el derecho quiere acercarse al amor, deberá abandonar toda pretensión de dominio sobre él y transformarse técnicamente en un discurso abierto, capaz 
de captar y aceptar la contingencia, la variabilidad y hasta la irracionalidad. Sobre todo, frente a la vida, el derecho debe estar dispuesto a ceder su lugar al no derecho. Por ello se pregunta Stefano Rodotà (2019) si es posible un amor de baja institucionalización que respete las identidades cambiantes sin refugiarse en las seguridades de un pasado constrictivo. Si nuestro país consagra y respeta a la igualdad y no discriminación como eje transversal del andamiaje jurídico constitucional, es necesario que las instituciones del sistema legal, incluyendo el matrimonio, estén al alcance de toda la ciudadanía. Excluir a las personas con diversa orientación sexual es un acto discriminatorio y una intromisión ilegítima por parte del Estado al ejercicio de los derechos fundamentales, el cual debe apartarse de esta regulación hegemónica y moralista del matrimonio. Sin embargo, existen mecanismos que deben respetarse que han sido establecidos por nuestra propia Constitución para alcanzar este cometido.

Adicionalmente, el problema jurídico que se ha planteado tiene relación directa con un debate que es de gran actualidad en la filosofía del derecho: la relación tensa entre derechos y rigidez constitucional. A pesar de que este trabajo no pretende explorar esta tensión ni cómo solucionarla, es pertinente indicar que, en países como el nuestro, en los cuales existe un sistema gradado y complejo de modificación de la Norma Suprema, esta tensión no es irrelevante y requiere, por parte de los intérpretes de la Constitución, un estudio minucioso pues está en juego el principio de supremacía constitucional como piedra angular del Estado constitucional.

El presente ensayo analizará los siguientes aspectos de la sentencia 1118-CN/19 de 12 de junio de 2019: primero, la desnaturalización del control concreto de constitucionalidad. Segundo, la interpretación efectuada a los enunciados normativos aplicables. Tercero, acerca del valor jurídico de las opiniones consultivas de la Corte Interamericana. Finalmente, algunas soluciones y conclusiones que abonarán el debate académico.

\section{LA DESNATURALIZACIÓN DEL CONTROL CONCRETO DE CONSTITUCIONALIDAD}

El control concreto de constitucionalidad en el Ecuador encuentra su fundamento en el citado art. 428 de la Constitución. Este mecanismo es desarrollado por la Ley Orgánica de Garantías Jurisdiccionales y Control Constitucional (en adelante "LOGJCC") en su art. 141, que dispone que el Control Concreto tiene como finalidad garantizar la constitucionalidad de la aplicación de las disposiciones jurídicas, dentro de los procesos judiciales. El siguiente artículo de este cuerpo legal dispone que el control concreto de 
constitucionalidad procede de dos maneras: de oficio, es decir, por solicitud expresa y directa de los administradores de justicia; y a petición de la o las partes procesales de una contienda judicial ${ }^{1}$. Sin embargo, el juez, para que la Corte proceda a realizar el control de constitucionalidad, debe tener una duda razonable y motivada de que la norma en cuestión es contraria a la constitución o a los tratados internacionales de derechos humanos que establezcan derechos más favorables que los reconocidos en la constitución. $\mathrm{Al}$ respecto, la Primera Corte ha señalado que

«la consulta de constitucionalidad no puede tornarse en un mecanismo de dilación de la justicia y vía de escape de las juezas y jueces del país (...) la consulta debería proceder única y exclusivamente cuando existe una motivación razonada de por qué acude a la consulta, pues, un proceder contrario deviene en jueces pasivos, no comprometidos con la protección de derechos, ya que estos se desatienden de la resolución de la causa sin un legítimo motivo constitucional (...) Así pues el concepto de duda razonable (...) no puede ser entendido de manera independiente al concepto de motivación (...) Las juezas y jueces constitucionales tienen la obligación de advertir y fundamentar ante la Corte Constitucional, la existencia de disposiciones normativas contrarias a la Constitución» (sentencia 030-13-SCN-CC, caso $0697-12-\mathrm{CN})$.

\section{Adicionalmente, la Corte Constitucional concluye que}

${ }^{1}$ El art. 142 de la mencionada ley dice:

Art. 142. Procedimiento.- Las juezas y jueces, las autoridades administrativas y servidoras y servidores de la Función Judicial aplicarán las disposiciones constitucionales, sin necesidad que se encuentren desarrolladas en otras normas de menor jerarquía. En las decisiones no se podrá restringir, menoscabar o inobservar su contenido.

En consecuencia, cualquier jueza o juez, de oficio o a petición de parte, sólo si tiene duda razonable y motivada de que una norma jurídica es contraria a la Constitución o a los instrumentos internacionales de derechos humanos que establezcan derechos más favorables que los reconocidos en la Constitución, suspenderá la tramitación de la causa y remitirá en consulta el expediente a la Corte Constitucional, la que en un plazo no mayor a cuarenta y cinco días resolverá sobre la constitucionalidad de la norma.

Si transcurrido el plazo previsto la Corte Constitucional no se pronuncia, el proceso seguirá sustanciándose. Si la Corte Constitucional resolviere luego de dicho plazo, la resolución no tendrá efecto retroactivo, pero quedará a salvo la acción extraordinaria de protección por parte de quien hubiere sido perjudicado por recibir un fallo o resolución contraria a la resolución de la Corte Constitucional.

No se suspenderá la tramitación de la causa, si la norma jurídica impugnada por la jueza o juez es resuelta en sentencia.

El tiempo de suspensión de la causa no se computará para efectos de la prescripción de la acción o del proceso. 
«la consulta de norma no puede tener como único fundamento la opinión de una de las partes sobre la constitucionalidad de la norma jurídica, sino la coherente y exhaustiva exposición de las razones que llevan al juez o jueza a no encontrar una interpretación de la norma o su aplicación al caso que sea compatible con la Constitución; es decir, la consulta debe ser adecuadamente motivada» (Sentencia 014-13-SCN-CC).

En este contexto, la Corte Constitucional (sentencia 036-13-SCN-CC) ha precisado que para que una consulta de norma dentro del control concreto de constitucionalidad pueda considerarse adecuadamente motivada, deberá contener al menos los siguientes presupuestos: (i) Identificación del enunciado normativo cuya constitucionalidad se consulta, obligación que está a cargo de los jueces y juezas, para denotar la relevancia constitucional. (ii) Identificación de los principios o reglas constitucionales que se presumen infringidos, exponiendo motivadamente las circunstancias y razones por las cuales dichos enunciados son determinantes en el proceso. (iii) Explicación y fundamentación de la relevancia de la norma puesta en duda, respecto de la decisión de un caso concreto, indicando las razones por las cuales el precepto normativo es indispensable para decidir sobre el fondo de la cuestión.

En este caso, los jueces tienen la obligación de suspender la tramitación de la causa y remitir en consulta el expediente del proceso que contenga la disposición normativa presuntamente contraria a la Constitución. Finalmente, conviene mencionar que la sentencia que dicte la Corte Constitucional tiene o puede tener dos efectos, con arreglo al art. 142 de la LOGJCC: (i) erga omnes, en aquellos casos en los cuales la Corte se pronuncie respecto de la compatibilidad de la disposición jurídica en cuestión, con las normas constitucionales. En este caso, el fallo tendrá los mismos efectos de las sentencias en el control abstracto de constitucionalidad. (ii) Inter partes, en los casos en que la Corte se pronuncia únicamente sobre la constitucionalidad de la aplicación de la norma jurídica.

En cuanto la sentencia 11-18-CN/19 de 12 de junio de 2019, la Sala de lo Penal de la Corte Provincial de Justicia de Pichincha realiza la consulta de norma acerca de la constitucionalidad del art. 67 de la Constitución ya que sería contraria a la OC 24/17. (Más adelante volveremos sobre esta supuesta antinomia.) Los jueces provinciales cometieron un error en la presentación y fundamentación de su consulta pues, de acuerdo con las normas aplicables y la jurisprudencia de la Corte, no es posible someter al control de constitucionalidad a una disposición de la Norma Suprema; pues si el objeto y fin de este control es la supremacía constitucional, dichas disposiciones son su parámetro para tal fin, lo cual es claramente indicado por el Voto salvado de la sentencia que analizamos (Corte Constitucional 
del Ecuador, voto salvado, caso 11-18-CN, 2019). Este error, tanto de los jueces provinciales como de la Corte Constitucional, es el primer aspecto de desnaturalización del control concreto de constitucionalidad. En consecuencia, la consulta en mención debió ser inadmitida por la Corte, al no reunir los requisitos exigidos por la LOGJCC y la jurisprudencia.

Adicionalmente, al revisar los puntos resolutivos de esta decisión, se puede advertir fácilmente que estos no guardan relación con los efectos que la ley prevé para el control concreto de constitucionalidad y que fueran mencionados líneas arriba. En efecto, la sentencia contiene tres puntos resolutivos: El primero, determina que la OC 24/17 es una interpretación auténtica y vinculante de las normas de la Convención Americana sobre Derechos Humanos (en adelante "CADH"), que forma parte del bloque de constitucionalidad para reconocer derechos o determinar el alcance de derechos en el Ecuador. Segundo, establece que no existe contradicción entre el texto constitucional con el convencional sino complementariedad. Tercero, dispone que el Tribunal consultante interprete el sistema normativo a la luz de esta sentencia y ordene que el Registro Civil registre el matrimonio de los accionantes.

Como se puede apreciar, la Corte no se pronuncia sobre la compatibilidad de una disposición jurídica con la Constitución ni sobre la constitucionalidad de la aplicación de la norma jurídica en el proceso judicial. Más aún, la Corte vulnera el principio de independencia judicial y se extralimita en sus funciones al disponerle al Tribunal consultante como debe interpretar las normas aplicables al caso, pues su función era exclusivamente determinar si la norma consultada es inconstitucional; la cual, como fuera analizado supra, es una disposición del propio texto constitucional y desnaturaliza al control concreto de constitucionalidad. Por lo tanto, de la lectura de la decisión de la sentencia 11-18-CN/19 de 12 de junio de 2019, se concluye que aquella es contraria a la naturaleza jurídica del control concreto de constitucionalidad y es inconsistente con la argumentación ofrecida por la Corte.

Por otra parte, aunque no es este estudio el objetivo central de este ensayo, la sentencia 10-18-CN/19 de 12 de junio de 2019 de la Corte, también sobre el matrimonio igualitario, acertadamente constriñe su examen a la compatibilidad entre los artículos 81 del Código Civil y 52 de la Ley de Gestión de la Identidad y Datos Civiles y señala que la sentencia tiene los mismos efectos erga omnes que una sentencia dictada dentro del control abstracto de constitucionalidad, de esta manera responde a la consulta de norma en el sentido de que dichas disposiciones son inconstitucionales. Así, la sentencia declara la inconstitucionalidad sustitutiva y sustractiva de los artículos sometidos al examen de constitucionalidad. De este modo, el 
Código Civil define ahora al matrimonio como un contrato solemne por el cual dos personas se unen con el fin de vivir juntos y auxiliarse mutuamente; mientras que la Ley de Gestión de la Identidad y Datos Civiles lo define como la unión entre dos personas y se celebra e inscribe ante la Dirección General de Registro Civil, Identificación y Cedulación.

No obstante, la conclusión a la que arriba la Corte en este caso denota una grave inconsistencia argumentativa que no puede pasar inadvertida. Efectivamente, si el art. 67 de la Constitución mantiene su texto y define al matrimonio como la unión entre hombre y mujer, esto implica que las sustracciones y adiciones realizadas por la Corte, dejan a textos infraconstitucionales que definen al matrimonio de una forma distinta a como lo define la Carta Magna; es decir, existe una antinomia que se produce debido a esta incongruencia argumentativa del fallo de mayoría de la Corte. Este tribunal siempre estuvo consiente que no tiene la facultad para modificar la redacción literal del art. 67 y, por ello, lo ha dejado intacto, pero sí ha alterado las definiciones constantes en cuerpos normativos de menor jerarquía, lo cual genera una antinomia en nuestro ordenamiento jurídico que está irresuelta. Consecuentemente, la interpretación forzada de la Corte genera una antinomia que sólo podría resolverse vía reforma del texto constitucional.

\section{LA INTERPRETACIÓN DE LOS ENUNCIADOS NORMATIVOS}

\section{APLICABLES}

La sentencia 11-18-CN/19 de 12 de junio de 2019 ha realizado su interpretación sobre al análisis y comparación de dos enunciados normativos que consideró necesarios para resolver los problemas jurídicos que se planteó. Por un lado, el segundo inciso del art. 67 de la Constitución dispone: «El matrimonio es la unión entre hombre y mujer, se fundará en el libre consentimiento de las personas contrayentes y en la igualdad de sus derechos, obligaciones y capacidad legal».

Por otro lado, el art. 17.2 de la CADH señala:

«Se reconoce el derecho del hombre y la mujer a contraer matrimonio y a fundar una familia si tienen la edad y las condiciones requeridas para ello por las leyes internas, en la medida en que éstas no afecten al principio de no discriminación establecido en esta Convención».

De la simple lectura de estas disposiciones, es posible colegir que se trata de enunciados normativos que difieren en su contenido y no podían ser asimilados ni comparados como tales. La Corte debía identificar con 
claridad de qué tipo de norma se trata la una y la otra a la luz de los principios de interpretación constitucional. Para este efecto, conviene acudir a tres autores a quienes la Corte Constitucional ya ha citado en sus decisiones, aunque en esta ocasión no efectuó tales precisiones.

El primero, Gustavo Zagrebelsky (2009, p. 110), quien ha señalado que la principal característica del Derecho actual es la superación del Estado de derecho legislativo por el Derecho por principios, aunque no desconoce el valor que poseen las reglas, no tanto así en materia constitucional donde los principios son más frecuentes. Este autor afirma que los principios no deben ser interpretados por el análisis del lenguaje sino por el contexto de su significado a la luz de los valores que representan históricamente, de modo que las palabras son solo una alusión. En cuanto a las reglas, éstas si pueden ser interpretadas mediante el lenguaje. La diferencia sustancial radica en que los principios ayudan para tomar posición ante situaciones que se encuentran indeterminadas y las reglas establecen criterios de actuación.

El segundo, Ricardo Guastini, sostiene que el análisis debe ser realizado desde el lenguaje y que, a partir del criterio de generalidad de la norma, es posible encontrar varios grados de esta característica mediante los cuales se expresan las normas en las disposiciones jurídicas. Así, distingue tres tipos de normas: reglas, principios y valores. A la primera la define como una disposición específica que posee una estructura que contiene «un enunciado condicional que conecta una consecuencia jurídica cualquiera con una clase de supuestos concretos» (Guastini, 2008, p. 74). En este sentido, tiene una función de premisa mayor de un silogismo y la consecuencia jurídica puede presentarse de múltiples maneras: una sanción, la generación de un derecho u obligación, adquirir una calidad, etc. De esta forma, son mandatos imperativos que admiten una verificación de cumplimiento o no. Por el otro lado, los principios constituyen preceptos más genéricos, establecen parámetros de comportamiento sin mencionar conductas concretas, de modo tal que le dotan de fundamento axiológico al sistema jurídico y son normas estructuralmente indeterminadas. Los valores, por su parte, son de tal importancia que trascienden el derecho y todas las disposiciones del ordenamiento, en algún momento, se remiten a ellos para ser interpretadas (Guastini, 2008, pp. 74-76).

El tercer autor, Robert Alexy, define a los principios como mandatos de optimización y las reglas son mandatos definitivos. Los principios deben ser cumplidos dentro de las posibilidades fácticas y jurídicas, en tanto que las reglas se cumplen o no. Si una regla es válida debe hacerse exactamente lo que ella exige, ni más ni menos. Consecuentemente, las reglas contienen determinaciones acerca de los fáctica y jurídicamente posible (Alexy, 2004, p. 162). Este autor añade: 
«La cuestión es, dónde y en qué medida son necesarias valoraciones, cómo debe ser determinada la relación de éstas con los métodos de interpretación jurídica y con los enunciados y conceptos de la dogmática jurídica, y cómo pueden ser racionalmente fundamentadas o justificadas esas valoraciones» (Alexy, 2012, p. 28).

Adicionalmente, el problema jurídico aquí presentado se relaciona directamente con ciertas preguntas relevantes con respecto a la teoría de la argumentación jurídica: ¿Qué interpretar? ¿Para qué interpretar? ¿Cuándo interpretar? ¿Cómo interpretar? No es posible, en este ensayo, analizar las complejidades y particularidades de estas preguntas, sino tan sólo dejar sentadas unas ideas y luego contrastarlas con el análisis realizado por la Corte dentro de la sentencia bajo estudio. Al respecto, Rodolfo Vigo sostiene que

«el "proceso" de argumentar, que concluirá como "resultado" en una argumentación, consiste en un razonamiento donde a partir de ciertos enunciados, premisas o juicios que se justifican con argumentos o razones, se obtiene mediante la respectiva inferencia, una respuesta acerca de un problema o pregunta que no es evidente. (...) Al argumentar tratamos de obtener un conocimiento que se busca desde otros conocimientos con los que se cuentan o se van obteniendo. La pregunta que moviliza no tiene una respuesta evidente, más bien, tiene — con mayor o menor amplitud— respuestas discutibles o verosímiles» (Vigo, 2017, p. 15).

Con estos criterios doctrinales, corresponde determinar qué tipo de norma es la que incorrectamente el fallo de mayoría de la Corte sometió a un examen de constitucionalidad y sí cabía una interpretación de la forma realizada por la Corte Constitucional.

El segundo inciso del art. 67 de la Constitución, norma que es sometida al cuestionado examen, es una disposición jurídica que define al matrimonio y determina ciertas características fundamentales que el constituyente ha considerado necesario protegerlas constitucionalmente. El texto es claro y concreto: el matrimonio es la unión entre hombre y mujer. En este contexto, es preciso determinar si se trata de una regla o un principio, a la luz de los parámetros que se han indicado anteriormente. El lenguaje de redacción es sumamente concreto y no implica ambigüedades que pueden encontrarse en otras normas redactadas como principio (v.gr. el derecho a la igualdad). Ante la pregunta de qué se entiende por matrimonio en el sistema legal ecuatoriano, la respuesta es unívoca: la unión entre hombre y mujer que se funda en el libre consentimiento de los contrayentes y en la igualdad de sus derechos y obligaciones. Evidentemente, estamos ante una disposición jurídica que debe considerarse como una regla, pues existe un nivel de concreción alto en su lenguaje, está sujeta a revisión de cumplimiento, existen claras consecuencias jurídicas al aplicar a situaciones de hecho específicas y, al ser una norma válida, debe ser cumplida en su tenor literal. 
Es un enunciado normativo que contiene un concepto o definición que no permite lugar a dudas. El enunciado que consta en la $\mathrm{CADH}$ es radicalmente diferente y no puede ser considerado como similar al de nuestra Constitución, como equivocadamente lo hizo la Corte, pues no contiene una definición de matrimonio, sino que reconoce el derecho a contraerlo para hombre y mujer. No existe, en esta disposición, una situación de hecho específica, con el alto nivel de concreción en el lenguaje ni las consecuencias jurídicas ante el presupuesto fáctico. Por lo tanto, la Corte encontró incorrectamente identidad en estas disposiciones y no determinó el tipo de norma de que se trata, la cual debía precisarse como regla, según los criterios abordados en esta sección.

Con respecto a las técnicas de interpretación utilizadas, el voto de minoría de la sentencia in comento es explícito al indicar que se debió utilizar el método de interpretación literal y sistemático, en virtud del lenguaje claro y concreto que posee la norma bajo estudio. Como se ha indicado, al tratarse de una regla con un alto nivel de concreción, se han eliminado las vaguedades del lenguaje casi en su totalidad. En este sentido, la norma no requería ser argumentada desde otra óptica, si consideramos que lo que se busca con la interpretación es la contestación a una pregunta o un problema cuya respuesta no es evidente. En este caso, la pregunta que se debía plantear para abordar este problema jurídico era: ¿Qué se entiende o cómo se define al matrimonio en el sistema jurídico del Ecuador? Para responderla, en primer lugar, es necesario acudir a lo señalado en la Constitución que determina cómo se interpretan las normas constitucionales:

Constitución, art. 427.- «Las normas constitucionales se interpretarán por el tenor literal que más se ajuste a la Constitución en su integralidad. En caso de duda, se interpretarán en el sentido que más favorezca a la plena vigencia de los derechos y que mejor respete la voluntad del constituyente, y de acuerdo con los principios generales de la interpretación constitucional».

Esta disposición señala, con meridiana claridad, que el primer método de interpretación es el literal que más se ajuste a la Constitución en su integralidad y, solo en caso de duda, utilizar otras técnicas interpretativas. La Corte reconoce el alto grado de concreción del art. 67 de la Norma Suprema, al afirmar:

«La expresión constitucional "El matrimonio es la unión entre hombre y mujer" reconoce un derecho humano fundamental y expresamente enuncia que es un derecho de las parejas heterosexuales. Hacer una interpretación de una norma clara y expresa requiere mucho cuidado y atención para no vulnerar la voluntad del constituyente y preservar la integridad del texto constitucional» (sentencia 11-18CN/19; énfasis añadido). 
En el siguiente párrafo señala que se trata de una proposición normativa que puede ser interpretada de muchas maneras. La pregunta que subsiste entonces es: Si es clara la norma, ¿cómo pueden existir varias formas de interpretación? La Corte, sencillamente, omite este análisis, revela graves inconsistencias argumentativas, parte de premisas inexistentes y de antinomias ilusorias. En una publicación que realizara hace unos años, el propio juez ponente de este fallo, ya lo advertía en estas palabras:

«La definición del matrimonio del año 1998 es mucho más amplia y menos discriminatoria que la Constitución del 2008. En la de 2008 SOLO los hombres y mujeres pueden contraer matrimonio (art. 67) y solo parejas de distinto sexo pueden adoptar (art. 68). Es decir, no cabe el matrimonio entre parejas homosexuales y se establece un prejuicio injustificable en contra de parejas del mismo sexo» (Ávila, 2012, p. 106; énfasis añadido).

En consecuencia, si la norma tiene ese alto nivel de claridad y no existe duda de la definición de matrimonio en nuestro país, el método interpretativo adecuado para contestar la pregunta planteada es el literal que aseguraba la voluntad del constituyente y la integralidad de la Constitución, de modo que la argumentación ofrecida por la Corte en este sentido es, igualmente, inconsistente.

\section{SOBRE EL VALOR JURÍDICO DE LAS OPINIONES CONSUltivas DE LA CORTE INTERAMERICANA}

Esta sección explorará brevemente uno de los temas más trascendentales que estudió la Corte al emitir su fallo: el valor jurídico de la OC-24-17. La pregunta que debía ser resuelta es: ¿Son las opiniones consultivas emitidas por la Corte Interamericana vinculantes para el Estado ecuatoriano? Para responder es necesario aproximarse al problema jurídico desde el derecho internacional público y no exclusivamente desde el Derecho Constitucional, como equivocadamente lo hizo la Corte en la sentencia que se comenta. Es erróneo pensar que el Derecho Internacional de los Derechos Humanos y el Derecho Constitucional se pueden asimilar y equiparar; se complementan sí, mas sus ámbitos de aplicación y formas de interpretación difieren. Es conveniente indicar que hay varios otros tribunales internacionales que gozan de facultades consultivas: Corte Internacional de Justicia, Corte Europea de Derechos Humanos, Tribunal Internacional del Derecho del Mar, etc. Por ello, es necesario considerar esta situación jurídica para conocer cuál es el valor legal de estas opiniones como fuentes de derecho internacional público. 
El art. 38 del Estatuto de la Corte Internacional de Justicia (en adelante, "CIJ") remite a las fuentes del derecho internacional público, al señalar qué instrumentos debe aplicar este tribunal al resolver las controversias que conoce. En particular, interesa para este estudio, el literal $\mathrm{d}:$ «(...) las decisiones judiciales y las doctrinas de los publicistas de mayor competencia de las distintas naciones, como medio auxiliar para la determinación de las reglas de derecho, sin perjuicio de lo dispuesto en el art. 59». De una lectura simple y llana de esta disposición, se puede colegir que las decisiones judiciales de tribunales internacionales- en los cuales se incluye la Corte Interamericana- son fuentes auxiliares de derecho internacional público; es decir, que no tienen un carácter principal ni primario al determinar las reglas de derecho.

Una vez determinado qué tipo de fuente del derecho internacional público es una decisión judicial, conviene determinar cuál es el valor normativo que tiene una opinión consultiva en el marco de esta misma rama de derecho. Al revisar la jurisprudencia de la CIJ, ya se ha pronunciado enfáticamente sobre su facultad consultiva: su respuesta es de carácter consultivo y no goza de fuerza obligatoria (30 de marzo de 1950, p. 71). Hay autores que ven en ellas una autoridad moral de carácter jurídicamente no vinculante. Naturalmente, existe otro sector de la doctrina que encuentra que, si bien tienen un carácter autoritativo, no implica que existan consecuencias si un Estado no sigue los lineamientos contenidos en la opinión de que se trate (Gross, 1967, p. 334). En este orden de ideas, conviene ser prudente para no desvalorar estas decisiones ni tampoco darles un valor desmesurado o inapropiado. Por consiguiente, en el marco del derecho internacional público, la CIJ ha destacado la diferencia entre su jurisdicción contenciosa y consultiva, y ésta última no tiene el mismo efecto vinculante que la primera, a pesar de que tengan un grado de autoridad.

A nivel de Corte Interamericana, al tratarse de un tribunal internacional que rige sus decisiones por el derecho internacional público, la situación no varía demasiado, aunque este organismo ha sido poco preciso en este sentido. No obstante, para determinar la naturaleza y alcance de su jurisdicción consultiva ha utilizado la jurisprudencia de la CIJ. En efecto, la Corte Interamericana ya señaló en su primera opinión consultiva (OC-1/82) que esta función

«tiene por finalidad coadyuvar al cumplimiento de las obligaciones internacionales de los Estados americanos en lo que concierne a la protección de los derechos humanos, así como al cumplimiento de las funciones que en este ámbito tienen atribuidas los distintos órganos de la OEA» (p. 25).

En otra opinión consultiva (OC-15/97) señaló: 
«La competencia consultiva de la Corte difiere de su competencia contenciosa en que no existen "partes" involucradas en el procedimiento consultivo, y no existe tampoco un litigio a resolver. El único propósito de la función consultiva es "la interpretación de esta Convención o de otros tratados concernientes a la protección de los derechos humanos en los Estados americanos". El hecho de que la competencia consultiva de la Corte pueda ser promovida por todos los Estados Miembros de la O.E.A. y órganos principales de ésta establece otra distinción entre las competencias consultiva y contenciosa de la Corte. 26. Consecuentemente la Corte advierte que el ejercicio de la función consultiva que le confiere la Convención Americana es de carácter multilateral y no litigioso, lo cual está fielmente reflejado en el Reglamento de la Corte, cuyo art. 62.1 establece que una solicitud de opinión consultiva será notificada a todos los "Estados Miembros", los cuales pueden presentar sus observaciones sobre la solicitud y participar en las audiencias públicas respecto de la misma. Además, aun cuando la opinión consultiva de la Corte no tiene el carácter vinculante de una sentencia en un caso contencioso, tiene, en cambio, efectos jurídicos innegables. De esta manera, es evidente que el Estado u órgano que solicita a la Corte una opinión consultiva no es el único titular de un interés legítimo en el resultado del procedimiento» (p. 25; énfasis añadido).

Es de gran interés revisar el voto individual del Juez Eduardo Vio Grossi dentro de la OC-24. En este voto, el juez recuerda que la Corte Interamericana, no puede; a través de su competencia consultiva, ejercer facultades normativas y modificar la Convención o la legislación nacional, lo cual está reservado a instancias nacionales o a los Estados Partes. La facultad interpretativa no puede implicar modificación del texto de un tratado sino determinar su alcance y significado si hubiera varias formas de aplicar la norma, lo cual está regulado por la Convención de Viena sobre el Derecho de los Tratados. Añade el juez Vio Grossi que la competencia no contenciosa o consultiva de la Corte «no consiste, entonces, en ordenar o disponer sino más bien en convencer. Su condición de no vinculante es la principal diferencia con la competencia contenciosa y es lo que fundamentalmente la caracteriza» (p. 12; énfasis añadido).

De estos criterios se colige lo siguiente: primero, el objetivo o finalidad de la función consultiva es la de coadyuvar a los Estados Partes de la $\mathrm{CADH}$ a que respeten sus obligaciones internacionales en materia de derechos humanos; es decir, se puede considerar que tiene un carácter preventivo. Segundo, ni la CIJ ni la Corte Interamericana les han otorgado fuerza obligatoria a sus opiniones consultivas, de manera que no pueden ser consideradas parte del instrumento internacional que interpretan, pues esto es otorgarle un valor desmesurado e inapropiado que conlleva una modificación de la CADH que no ha sido consentida por los Estado Partes, piedra angular para la creación de un tratado internacional, con arreglo a la Convención de Viena sobre el Derecho de los Tratados. 
Es necesario advertir, sin embargo, que sería plausible -o habría sidoque el caso que conoció la Corte, vía consulta de norma, agote sus instancias nacionales y sea sometido al mecanismo de peticiones individuales del sistema interamericano de protección de derechos humanos. En el caso de obtener una resolución favorable para los peticionarios, la Comisión o Corte Interamericana ordenaría reparaciones materiales e inmateriales que podrían haber incluido, entre otras, reformas legales que involucren el reconocimiento del matrimonio civil para parejas del mismo sexo. De ser este el caso, con arreglo al art. 68.1 de la CADH, el Ecuador habría tenido que cumplir con el fallo, sin necesidad de recurrir a las "peripecias" argumentativas que utilizó nuestra Corte en el fallo bajo análisis. En este sentido, se trata de una decisión judicial de cumplimiento obligatorio que habría derivado en una modificación constitucional inclusive.

\section{POSIBLES SOLUCIONES Y CONSIDERACIONES ADICIONALES}

A pesar de que no es el objetivo central de este artículo, encontrar la corrección de la antinomia producida por las decisiones de la Corte Constitucional no tiene una salida simple y de corto plazo. En primer lugar, el art. 440 de la Constitución señala enfáticamente que las sentencias y los autos de este organismo son definitivos e inapelables, de manera que no existe un recurso judicial que pueda ser interpuesto para rever la decisión de la Corte, como sería un recurso de nulidad en la justicia ordinaria. En esta perspectiva, existen únicamente dos salidas jurídicamente viables:

La primera, tiene su asidero legal en el art. 2.3 de la LOGJCC, el cual trata sobre la obligatoriedad del precedente constitucional. Los alcances de esta disposición no son materia del presente estudio, sin embargo, este enunciado normativo señala que los parámetros interpretativos fijados por el máximo órgano de control constitucional tienen fuerza vinculante y que sólo puede alejarse de sus precedentes de forma explícita y argumentada, siempre que garantice la progresividad de los derechos y la vigencia del estado constitucional de derechos y justicia. En este orden de ideas, la Corte podría alejarse de su precedente; no obstante, según lo que se ha analizado en este ensayo, tal decisión no garantizaría la progresividad de los derechos constitucionales; en este caso, la igualdad y no discriminación y el acceso igualitario de toda la ciudadanía a las instituciones civiles que consagra el ordenamiento jurídico ecuatoriano. Es muy poco probable que la Corte tome una decisión en este sentido, al menos, en el corto plazo.

La segunda alternativa es igualmente compleja y requiere un largo camino para alcanzarse: una modificación al texto constitucional. El 
procedimiento de reforma de la Constitución está establecido en sus arts. 441 a 444, los cuales prevén tres mecanismos para tal fin: enmienda, reforma parcial y cambio constitucional. Para determinar cuál es el procedimiento que se debe seguir, la propia norma constitucional ha indicado cuatro criterios que; si bien es cierto son altamente ambiguos y, en ocasiones, puede tornarse muy dificultoso determinarlo, no es menos cierto que, para el caso que nos ocupa, se podría determinar con un alto grado de certeza.

Estos criterios son: si la modificación altera la estructura fundamental del Estado o sus elementos constitutivos, restringe derechos o garantías constitucionales y si cambia el procedimiento de reforma a la Constitución. Si la modificación no reúne ninguno de los criterios señalados se deberá tramitar como enmienda. Por su parte, si la reforma implica una alteración a la estructura fundamental del Estado o sus elementos constitutivos se la realizará como reforma parcial. Finalmente, a pesar de que la Constitución no lo diga expresamente, con arreglo al art. 101 num. 2 de la LOGJCC, cualquier proyecto normativo que tenga por objeto o efecto restringir el alcance de los derechos y garantías constitucionales o modificar el régimen procedimental de reforma a la Constitución sólo podrá tramitarse a través de una Asamblea Constituyente. En consecuencia, al tratarse de una reforma que sería progresiva en derechos, el asunto debería tramitarse como enmienda, toda vez que no altera la estructura fundamental del Estado ni sus elementos constitutivos de conformidad con el art. 441 de la norma suprema.

Para finalizar este análisis, se propone un ejemplo. A partir del art. 56, la Constitución española regula el funcionamiento de la Corona, entre varios, el aspecto de la sucesión hereditaria. Las disposiciones aplicables hablan del Rey, del Príncipe heredero y no se le asignan funciones constitucionales a la Reina, salvo las de Regencia. Esto significa que España no podría nombrar una Reina, pues la Constitución no lo prevé así de la lectura integral de su texto. Resulta claro que se trata de una norma constitucional que es discriminatoria, pues no existe una justificación razonable y objetiva para esta diferenciación sobre la base del sexo de la persona aspirante a la Corona. No obstante, sería muy poco probable que el Tribunal Constitucional español realice un control de constitucionalidad de dichos artículos y que, a través de una decisión judicial, permita que una mujer pueda acceder a tal cargo, incluso si se considera que es un escenario totalmente factible dado que el Rey actual tiene tres hijas, puesto que la única vía posible para tal efecto es la reforma constitucional. En términos simples, eso fue lo que hizo nuestra Corte con respecto al matrimonio igualitario y su fallo vulnera el principio de supremacía constitucional, de división de poderes y el régimen de reforma constitucional. 


\section{Conclusiones}

1. Este ensayo no ha pretendido abarcar todas las aristas que involucra un análisis de la institución del matrimonio civil para parejas homosexuales ni sus imbricaciones con el derecho a la igualdad y no discriminación, sino destacar ciertos aspectos fundamentales de la sentencia 11-18-CN/19 que constituyen inconsistencias argumentativas que han desembocado en conclusiones incoherentes. En la práctica, este fallo le ha dado un significado del cual carece el inciso segundo del art. 67 de la Constitución, toda vez que esta disposición mantiene su texto original y las normas infra constitucionales correlativas no guardan armonía con la Norma Suprema.

2. La consulta de norma remitida a la Corte Constitucional, con el fin de que ejerza el control concreto de constitucionalidad, no reunía los requisitos exigidos por la Ley y debió ser inadmitida. Esta omisión constituye el primer error que desnaturaliza esta figura de control constitucional. El segundo, la Corte no se pronuncia sobre la compatibilidad de una disposición jurídica con la constitución, ni sobre la constitucionalidad de la aplicación de la norma jurídica en el proceso judicial. Más aún, la Corte vulnera el principio de independencia judicial y se extralimita en sus funciones al disponerle al Tribunal consultante como debe interpretar las normas aplicables al caso, pues su función era exclusivamente determinar si la norma consultada es inconstitucional, la cual es una disposición del propio texto constitucional y desnaturaliza al control concreto de constitucionalidad.

3. Los enunciados normativos que fueron interpretados por la Corte Constitucional tienen un alto nivel de claridad y no existe duda de la definición de matrimonio en nuestro país, el método interpretativo adecuado para contestar la pregunta planteada es el literal que aseguraba la voluntad del constituyente y la integralidad de la Constitución, de modo que la argumentación ofrecida por la Corte en este sentido es inconsistente.

4. El objetivo o finalidad de la función consultiva de la Corte Interamericana es la de coadyuvar a los Estados Partes de la CADH a que respeten sus obligaciones internacionales en materia de derechos humanos; es decir, se puede considerar que tiene un carácter preventivo. Segundo, ni la CIJ ni la Corte Interamericana les han otorgado fuerza obligatoria a sus opiniones consultivas, de manera que no pueden ser consideradas parte del instrumento internacional que interpretan, pues esto es otorgarle un valor desmesurado e inapropiado que conlleva una modificación de la CADH que no ha sido consentida por los Estado Partes, piedra angular para la creación de un tratado internacional, con arreglo a la Convención de Viena sobre el Derecho de los Tratados. 
5. Las instituciones del ordenamiento jurídico deben estar al alcance de toda la ciudadanía; no obstante, es necesario respetar los procedimientos que para el efecto ha creado la propia Constitución. Así, la vía correcta para alcanzar estos fines era una modificación a la disposición constitucional que fue motivo del fallo que se comenta 


\section{REFERENCIAS}

Alexy, R. (2004). El concepto y la validez del derecho. Barcelona: Gedisa.

Alexy, R. (2012). Teoría de la argumentación jurídica (Trad. M. Atienza e I. Espejo). Madrid: Centro de Estudios Constitucionales.

Ávila, R. (2012). Los derechos y sus garantías. Quito: Corte Constitucional para el Período de Transición.

Corte Constitucional del Ecuador, sentencia 001-13-SCN-CC, caso 0535-12-CN (Jueces del Tribunal Distrital de lo Contencioso Administrativo 3 con sede en Cuenca), de 13-II-2013.

Corte Constitucional del Ecuador, sentencia 003-14-SN-CC, de 17-IX-2014.

Corte Constitucional del Ecuador, sentencia 014-13-SCN-CC, de 12-IV-2013.

Corte Constitucional del Ecuador, sentencia 030-13-SCN-CC, caso 0697-12-CN, petición de consulta de norma efectuada por la Corte Nacional de Justicia, de 14-V-2013.

Corte Constitucional del Ecuador, sentencia 036-13-SCN-CC, caso 0047-11-CN, petición de consulta de norma efectuada por el Juez de lo Civil de Pastaza, de 14-V-2013.

Corte Constitucional del Ecuador, sentencia 10-18-CN/19 de 12-VI-2019.

Corte Constitucional del Ecuador, sentencia 11-18-CN/19, de 12-VI-2019.

Corte Interamericana de Derechos Humanos, opinión consultiva OC-1/82, "Otros tratados", objeto de la función consultiva de la Corte (art. 64 de la Convención Americana sobre Derechos Humanos), solicitada por el Estado de Perú, de 24-IX-1982.

Corte Interamericana de Derechos Humanos, opinión consultiva OC-15/97, "Informes de la Comisión Interamericana de Derechos Humanos" (art. 51 de la Convención Americana sobre Derechos Humanos), solicitada por el Estado de Chile, de 14XI-1997.

Corte Interamericana de Derechos Humanos, opinión consultiva OC-24/17, relativa a la identidad de género, e igualdad y no discriminación a parejas del mismo sexo, solicitada por la República de Costa Rica, de 24-XI-2017.

Corte Internacional de Justicia. (30-III-1950). Opinión consultiva de la Corte Internacional de Justicia sobre interpretación de los tratados de paz. ICJ Reports.

Gross, L. (1967). The International Court of Justice and the United Nations. Recueil des cours de l'Académie de Droit International de la Haye, 120(1), 313-440.

Guastini, R. (2008). Teoría e ideología de la interpretación constitucional. Madrid: IIJ/UNAM.

Rodotà, S. (2019). El derecho de amor. Madrid: Trotta.

Vigo, R. (2017). La interpretación (argumentación) en el Estado Constitucional. Valencia: Tirant lo Blanch.

Zagrebelsky, G. (2009). El derecho dúctil. Madrid: Trotta. 